\title{
DEEPWEB: 0 Lado Sombrio da Internet
}

DEEPWEB: The Internet's Dark Side

João Paulo Falavinha Marcon'1

Thais Pereira Dias ${ }^{2}$

\section{RESUMO}

A DeepWeb é um nível da internet no qual não existem limites para os atos que são lá praticados: fotos e vídeos de muita violência são espalhados sem nenhum tipo de filtro. $O$ que existe de mais perigoso na DeepWeb é o seu anonimato, pois, quem a utiliza, dificilmente é rastreado, posto que muitas ferramentas são usadas para esconder a verdadeira identidade e localização do usuário. Com o passar dos anos, as histórias encontradas na DeepWeb vêm assustando pessoas em várias partes do mundo. Neste artigo, será apresentado, um pouco, do que acontece "no lado sombrio da internet" e o que o Governo Brasileiro tem feito para lidar com essa situação.

Palavras-chave: Internet; DeepWeb; anonimato; crimes; Marco Civil da Internet

\section{ABSTRACT}

The DeepWeb is an internet's level where there are no limits to the acts that are practiced in it: a lot of photos and videos of strong violence are spread without any kind of filter. Which is most dangerous in DeepWeb is its anonymity, because who uses is it, it is hardly traced, as many tools are used to hide his true identity and location. Over the years, the stories found in DeepWeb have been scaring many people in various parts of the world. This article aims to explain a bit about what happens in "the dark side of internet" and how Brazilian's Government has been handling these situations.

Keywords: Internet; DeepWeb; anonymity; information; crimes; Internet's Civil Regulation

\section{Introdução}

A internet tornou-se uma grande e útil ferramenta de pesquisa e comunicação, indispensável para o mundo moderno, sendo difícil encontrar alguém que não a utilize,

\footnotetext{
${ }^{1}$ Advogado. Especialista em Direito e Negócios Internacionais. Mestre em Ciência Política. Professor nas Faculdades OPET. Membro do Núcleo de Estudos e Pesquisas em Relações Internacionais (NEPRWFPR). Curitiba, Brasil.

${ }^{2}$ Graduanda do curso de Direito das Faculdades OPET, Curitiba, Brasil.

Conjuntura Global, Vol.3, n. 4, out./dez., 2014, p. 233-243. 
hodiernamente. Mas o que muitos não sabem, é que ela não é usada, apenas, para conversar com amigos, fazer pesquisas acadêmicas, ou saber das últimas notícias do dia, pois muitas pessoas valem-se dela, anonimamente, para cometer diversas atrocidades sem serem identificadas e devidamente punidas, conforme será demonstrado ao longo deste artigo. 0 presente estrutura-se da seguinte maneira: primeiramente, noções gerais acerca da Internet e da DeepWeb; sucessivamente, serão apresentados alguns atos delituosos praticados na última; em seguida, apresentar-se-á como o Estado Brasileiro buscou normatizar o uso da Internet; por fim, serão trazidas algumas considerações sobre o estudo feito.

\title{
Internet
}

Quem, hoje, não está conectado à Internet? Pessoas passam, praticamente, 24 horas conectadas, seja no computador, no celular, ou em qualquer lugar onde possam ler emails, enviar fotos e conversar com amigos. É quase inimaginável conhecer alguém, nas grandes cidades, sem acesso à Internet, já que ela permite conexão e compartilhamento fácil e rápido de informações com vários computadores ao redor do mundo, em tempo real e instantâneo.

\begin{abstract}
Os computadores compartilham informações de diferentes formas e conteúdos, disponibilizando vários serviços de diversas mídias (textos, imagens, vídeo e som). Aliás, essa parte multimídia da Internet é chamada WWW. Essa comunicação entre tantos sistemas é viável devido a um protocolo de comunicação chamado TCP/IP. O TCP começou a ser projetado nos anos 60, a partir de interesses militares dos Estados Unidos, como uma rede descentralizada, de fato sem poder central, para garantir sua manutenção e operabilidade, mesmo em condições adversas, como uma guerra por exemplo. Sendo assim, a Internet não tem dono ou uma empresa encarregada de administrá-la. Cada rede individual conectada à Internet pode ser administrada por uma entidade governamental, uma empresa ou uma instituição educacional. Mas, a Internet, como um todo, não tem um dono ou um poder central. A Internet tem aplicações as mais diversas possíveis: a localização de pessoas, empresas e assuntos (Pesquisa); a troca de informações (Comunicação); a ministração de cursos (Educação), a apresentação de produtos e serviços (Marketing); a comercialização de produtos e serviços (Vendas); o uso de jogos, vídeos, sons e diversos passatempos (Entretenimento), entre outros. ${ }^{3}$
\end{abstract}

Muitos usuários apenas aproveitam, com viés benéfico, as facilidades que a Internet tem a oferecer, mas, assim como muitas pessoas divertem-se no whatsapp ou postam fotos de viagem no Facebook, bem como relatam histórias engraçadas em seus

\footnotetext{
${ }^{3}$ Disponível em <http://www.ufpa.br>. Acesso em: 29 nov. de 2014.

Conjuntura Global, Vol.3, n. 4, out./dez., 2014, p. 233-243.
} 
blogs, existem indivíduos que não tem boas intenções e encontram, no ambiente virtual, o local perfeito para cometer "crimes virtuais". Não se sabe, ao certo, quem são essas pessoas, pois, na Internet, consegue-se, com facilidade, manter o anonimato: baixando um programa simples no computador, qualquer usuário pode esconder o seu IP (Protocolo de Internet), o qual possibilita saber de onde foi originado determinada publicação. Por isso, os crimes na Internet estão crescendo, cada vez mais, nos últimos anos, exatamente pela falta de controle estatal.

Resumidamente, pode-se apresentar o surgimento da Internet como sendo baseada em códigos e, muito antes do modelo conhecido hoje, existiram outras tecnologias que contribuíram para o aperfeiçoamento daquela, como o telégrafo e o sistema binário, como segue:

É a partir de códigos construídos por esse sistema binário (padronizado com os numerais 0 e 1) que os computadores realizam o processamento de dados, sendo que cada bit corresponde a um dígito dessas sequências. Sem eles, não seria possível nem sequer realizar a leitura dessas informações. ${ }^{4}$

A internet, tal qual hoje é conhecida, teve sua origem em 1960, na Guerra Fria, com os conflitos entre os Estados Unidos e a União Soviética, pois os militares norteamericanos precisavam de um sistema que possibilitasse comunicação em longas distâncias, sem que esta pudesse ser cortada ou extraviada. Foi, então, que Paul Baran teve a ideia de criar uma rede com vários trajetos para que pudesse chegar ao seu destino, assimilando-se a uma teia, por isso a expressão $W E B$ que, em inglês, significa "teia de aranha". O primeiro experimento recebeu o nome de packet switching, ou "troca de pacotes", em português. Depois de alguns anos, os estadunidenses decidiram colocar a ideia de Baran em prática.

A ARPANET, uma rede de armazenamento de dados que inicialmente conectou algumas universidades e centros de pesquisa: as sedes da Universidade da Califórnia em Los Angeles e Santa Barbara; o Instituto de Pesquisa de Stanford e a Universidade de Utah. Desse modo, tudo ficaria armazenado virtualmente, sem correr o risco de sofrer danos materiais. Além disso, pouco tempo seria perdido na troca de dados. Em outubro de 1969, a ARPANET teve seu primeiro sucesso ao transmitir uma mensagem através de sua rede, da Universidade de Los Angeles até o instituto em Stanford, em uma distância de quase 650 quilômetros. Ao mesmo tempo, entretanto, essa tentativa resultou em fracasso: o conteúdo transmitido - a palavra "login" - chegou incompleto ao receptor,

\footnotetext{
${ }^{4}$ Ibdem. 
pois o sistema caiu antes da recepção da terceira letra do termo enviado. ${ }^{5}$

Os anos que se seguiram foram utilizados para pesquisas com a internet, tentando melhorá-la e deixá-la estável. Muitos estudos paralelos foram feitos, mas, depois de algum tempo, com Robert Kahnet e Vint Cerf, foi criado o TCP/IP, que serviria para conectar todas as redes. Depois que o sistema da ARPANET começou a crescer, houve sobrecarga, fazendo com que, mais tarde, juntasse-se à empresa National Science Foundation.

Depois de sua criação, a Internet conseguiu cada vez mais adeptos. Em 1979 surgiram os emoticons, que são símbolos, figuras, desenhos e animações utilizados para demonstrar sentimentos e reações, sendo que, muitas vezes, um deles "vale mais do que mil palavras". É claro que, por muito tempo, a Internet foi um meio de diversão, os emails trouxeram maior praticidade à troca de contatos, porém, em 1971, foi concebido o que, até hoje, é um problema para qualquer pessoa que utilize a internet: o vírus de computador.

0 primeiro vírus conhecido foi chamado de The Creeper, que invadia o computador e mostrava a mensagem: “Eu sou assustador, pegue-me se for capaz!”. No início da Internet, esses vírus não eram grandes problemas porque não ameaçavam, de forma grave, o pleno funcionamento do equipamento, por terem caráter mais de "brincadeira".

Em 1980, a Internet começou a ganhar espaço entre as "pessoas comuns", com a criação das "salas de bate-papo" (chat rooms). Passando-se os anos, foi criada a possibilidade de se navegar de um site para o outro com a invenção do HTTP e HTML, o $W W W$ (world wide web) ganhou cada vez mais adeptos e a Internet começou a se expandir de forma absurda, com milhões de usuários, em pouco tempo.

Segundo o IBOPE (Instituto Brasileiro de Opinião Pública e Estatística), o Brasil é o terceiro país em número de usuários ativos na Internet ${ }^{6}$, e essa quantia tende a crescer. Qualquer pessoa pode criar uma página na Internet e expor suas ideias, opiniões e desejos, e isso é feito de forma livre, não existem muitas restrições, haja vista a defesa do princípio constitucional da "liberdade de expressão e de livre pensamento". Hoje, ao acessar um site de notícias, é possível escrever o que se pensa sobre o assunto porque muitos veículos de notícia colocam, juntamente com o comentário, que a opinião é

\footnotetext{
${ }^{5}$ Disponível em <www.tecmundo.com.br>. Acesso em: 29 nov. de 2014.

Conjuntura Global, Vol.3, n. 4, out./dez., 2014, p. 233-243.
} 
pessoal e não significa ser o posicionamento da empresa, não sendo raro, também, encontrar discussões nesses grupos.

O que a Internet mais facilita é a comunicação: não se faz necessário marcar reuniões presenciais; ir, pessoalmente, entregar documentos, pois tudo isso pode ser feito por aquela. Pessoas se encontram cada vez menos, pessoalmente, para solucionar problemas, "tudo" é feito por um email ou mensagem em alguma rede social, vive-se em uma nova era, em que seres humanos têm reduzido contato físico uns com os outros, começam e terminam relacionamentos em "cliques", compram presentes na Internet e mandam entregá-lo no domicílio do aniversariante, sequer encontrando a pessoa, nem para dar um abraço de parabéns.

\section{O lado sombrio da Internet}

Existem, porém, coisas que acontecem na Internet que não são nada agradáveis, pois há pessoas que querem fazer coisas muitas cruéis, mas, como fazê-lo sem ser pego? Umas das possibilidades é a Internet, e, pensando nesses indivíduos não bem intencionados, que foi criado um local especifico na Internet onde o anonimato é de 100\%, denominado Deep Web e sobre o qual serão tecidos mais comentários adiante.

O Google - um dos sítios de pesquisa mais conhecido entre usuários da Internet pode ser utilizado por qualquer pessoa que navegue nela, por meio do sistema criado por Larry Page e Sergey Brin, na Universidade de Stanford, primeiramente chamado de BackRub, e, mais tarde, transformado em Google, como conhecido hoje. Tornou-se a maior ferramenta de pesquisa na Internet, encontrando-se um acervo infinito de informações, acessível com apenas algumas palavras e "cliques". O Google surgiu em 1998 como empresa, começando, apenas, em uma garagem e, a partir daí, não parou mais de crescer, revolucionando a experiência na Internet, e ficando conhecida como "A Gigante".

Pode-se pensar, na Internet, como possuindo vários "níveis": acima de todos está o Google, já citado. Há, um pouco mais abaixo, com acesso mais restrito, a SurfWeb, sendo que algumas coisas da DeepWeb são salvas na SurfWeb, mas este, ainda, é um "nível" não tão obscuro quanto aquele porquanto, lá, ficam algumas coisas salvas, mas depois de um tempo também desaparecem. Explica-se:

\footnotetext{
${ }^{6}$ Disponível em <http://www.ibope.com.br>. Acesso em: 29 nov. de 2014.

Conjuntura Global, Vol.3, n. 4, out./dez., 2014, p. 233-243.
} 
A Surface Web ou Internet superficial é a parte da World Wide Web indexada pelos motores de busca. A parte que não é indexada chama-se Deep Web. Motores de busca constroem um banco de dados através de programas chamados Web Crawlers ou spiders (aranhas) que começam com uma lista de páginas de internet conhecidas. Esse programa pega uma cópia de cada página e indexa-a, guardando informações importantes que permitirão que a página seja facilmente recuperada mais tarde. Qualquer hiperlink para novas páginas são adicionadas para a lista de páginas para serem indexadas. Eventualmente todas as páginas acessíveis são indexadas a menos que exceda os limites do motor de busca. 0 conjunto de páginas acessíveis definem a Surface Web. Por diversas razões (como o Protocolo de Exclusão de Robôs, links gerados por JavaScript e Flash, proteção de senhas) algumas páginas não podem ser acessadas pelos Web Crawlers. Essas páginas compõem a Deep Web. Em Janeiro de 2014 as páginas indexadas eram pelo menos 15 bilhões de páginas. ${ }^{7}$

A DeepWeb seria o nível mais profundo da Internet, o seu "lado obscuro". Não se permite, a qualquer pessoa, que tenha acesso a essa rede, pois são necessários vários programas específicos para usa-la, não se admitindo navegadores comuns como o Google. É forçoso que se tenha navegador específico, muito conhecimento de sistemas de computação e de Internet, posto que existe grande número de vírus que são testados na DeepWeb, então, a probabilidade de avarias no computador é muito alta. Ademais, devese ter um programa que esconda a localização do usuário para este não ser pego, já que alguns países proíbem, expressamente, o acesso à DeepWeb.

O que acontece na DeepWeb é a inexistência de "filtros" como os disponíveis no Google, o que possibilita encontrar vídeos e fotos de crimes, assassinatos, estupros, experiências ilegais, crueldades com animais, pedofilia, venda de drogas, tutoriais de como fazer bombas, hackers e muitas pessoas que oferecem esses serviços, por isso é altamente recomendável não acessar a DeepWeb e, repita-se, o acesso a ela é configurado conduta criminosa em vários países. Porém, nem só coisas ruins podem ser encontradas na DeepWeb, existe muito conteúdo interessante por lá, é possível ampliar conhecimentos em determinadas áreas com livros, vídeos e tutorias do mundo inteiro, como se pode inferir do relato que segue:

No passeio pela DW encontrei uma biblioteca com livros raros, serviços de mensagens instantâneas, cerca de 50 GB de livros sobre religião, psicologia e outros assuntos curiosos, além de acervos de músicas e filmes - dos quais não sabemos a procedência. Há ainda uma espécie de Yahoo! Respostas, onde pessoas anônimas perguntam e respondem sobre os mais diversos temas, e o

\footnotetext{
${ }^{7}$ Disponível em <http://pt.wikipedia.org >. Acesso em: 29 nov. de 2014.

Conjuntura Global, Vol.3, n. 4, out./dez., 2014, p. 233-243.
} 
A questão da DeepWeb é o que se quer encontrar, porquanto cabe, a cada um, saber filtrar o que quer aprender com isso. 0 que mais assombra, ao se abordar o tema da DeepWeb, são suas "lendas", sendo, algumas, muito conhecidas por pessoas que navegaram pelo canal e contaram o que viram. Algumas das mais conhecidas são as que seguem. A “Centopeia Humana” é, exatamente, como o filme de ficção de mesmo nome, cujo mote são experimentos humanos, nos quais cirurgiões conectam pessoas com intervenções médicas, pelo anus, e quebrando seus ossos das pernas e braços, a fim de criar a dita "Centopeia Humana". Depois, pesquisam as reações de seus experimentos, podendo-se, no Google, localizar fotos do referido "experimento", encontradas na DeepWeb.

Entre todas as "lendas" encontradas na DeepWeb, talvez essa seja a mais assustadora: as "bonecas humanas". Elas são feitas sob encomenda, permitindo, destarte, ao "comprador", escolher como quer sua "boneca" (loira, ruiva, morena etc.). 0 problema é que são crianças reais, "compradas" em orfanatos e, segundo um relato, um dos "vendedores" explica como cria essas bonecas: ele "adquire" as meninas, de até 12 anos de idade, nos orfanatos, leva-as para a sua casa e, no outro dia, submete-as a cirurgias em que são amputados braços e pernas, e são retiradas as cordas vocais. Todos os dentes são substituídos por próteses de silicone e, depois que acordam, são deixadas sozinhas em um quarto com uma mamadeira na prateleira, devendo fazer o que podem para conseguir se alimentar.

Após alguns dias, começam a ser torturadas e "ensinadas" que são escravas sexuais e o que devem fazer para satisfazer seus "donos". Ademais, são deixadas sozinhas o dia todo, assistindo a gravações das torturas, com fones nos ouvidos por horas com o volume muito alto, o que as deixa surdas, e usam-se laser nos olhos para deixa-las cegas. Feito todo esse processo, são colocados próteses de porcelana nos braços e nas pernas, e, finalmente, são devidamente entregues aos seus "donos", juntamente com um manual ensinando que são totalmente dependentes destes, por isso, é necessário alimentá-las e levá-las ao banheiro uma vez ao dia, tendo o "prazo de validade" de 2 anos.

No Google é possível encontrar algumas fotos das "bonecas", porém as imagens

\footnotetext{
8 Disponível em <www.uol.com.br>. Acesso em: 29 nov. de 2014.
}

Conjuntura Global, Vol.3, n. 4, out./dez., 2014, p. 233-243. 
são muito fortes, e como não são bem "cuidadas" elas acabam morrendo de fome ou hemorragia. É extremamente difícil afirmar, de maneira contundente e inconteste, se essas histórias são verdadeiras ou não, tendo sido, as únicas, realmente, confirmadas, a da "Centopeia Humana" (supramencionada) e o "estupro de recém-nascidos" (que se optou por não relatar, haja vista a gravidade do ato), pois, recentemente, um homem foi preso nos EUA, já que o FBI (Federal Bureau of Investigation) conseguiu localizá-lo na DeepWeb, por ter divulgado que iria estuprar sua filha assim que nascesse.

No Brasil, a Policia Civil, através da "Operação DarkNet", cumpriu mais de 100 mandados de prisões contra pessoas que utilizaram a DeepWeb para crimes de pedofilia, "quebrando" o sistema que camuflava a localização e encontrou tais usuários, bem como mais de 90 indivíduos que compartilhavam material com pornografia infantil. "No decorrer da investigação iniciada há um ano, pelo menos seis crianças foram resgatadas de situações de abuso ou do iminente estupro, em diversos locais do Brasil. Em um dos casos, um pai relatava que iria abusar da filha assim que ela nascesse." 9

\section{Leis contra crimes na Internet}

Com o número crescente de crimes cometidos por meio da Internet, houve a necessidade da criação de leis para punir as pessoas que usam, de forma ilícita, essa ferramenta, trazendo-se, a título exemplificativo, mal não como um rol taxativo: "a Lei Carolina Dieckmann" e o "Marco Civil da Internet", as quais serão, doravante, descritas de modo breve.

A Lei no 12.737/2012 alterou o Código Penal e ficou, popularmente, conhecida como "Lei Carolina Dieckmann", depois que fotos íntimas da atriz homônima foram, desautorizadamente, divulgadas na Internet, tipificando várias condutas como delituosas, assim como estipulou diversas punições. Essa norma foi muito importante, pois, antes dela, não existia no Código Penal, tampouco em legislações especiais esparsas, punições para tais atitudes, promovendo a impunidade dos que cometiam os já referidos atos atrozes. Hoje isso não mais ocorre, posto que a "privacidade" na Internet está sendo cada vez mais assegurada pela lei, como se pode inferir do dispositivo que se reproduz:

Invasão de dispositivo informático: Art. 154-A. Invadir dispositivo informático alheio, conectado ou não à rede de computadores, mediante violação indevida de mecanismo de segurança e com o fim de obter, adulterar ou destruir dados

\footnotetext{
${ }^{9}$ Disponível em $<<$ www.uol.com.br $>>$. Acesso em: 29 nov. de 2014.

Conjuntura Global, Vol.3, n. 4, out./dez., 2014, p. 233-243.
} 
ou informações sem autorização expressa ou tácita do titular do dispositivo ou instalar vulnerabilidades para obter vantagem ilícita: Pena - detenção, de 3 (três) meses a 1 (um) ano, e multa. ${ }^{10}$

0 mais importante, nesta lei, é a garantia da privacidade, aliada à proteção das informações e conteúdo compartilhados na "rede mundial de computadores".

Já o “Marco Civil da Internet”, consistente na Lei no 12.965/14, estabelece regras para a devida utilização da Internet, entre as quais: liberdade de expressão, proteção da privacidade e garantia de neutralidade da rede. Ao entrar em vigor, a regra dispôs que a privacidade dos usuários deve ser garantida por empresas, as informações que são fornecidas para estas não poderão ser repassadas a terceiros, ficando assegurada, também, a privacidade nas comunicações como nos emails, por exemplo. Também é possível a retirada de conteúdo que viole a privacidade de terceiros.

\begin{abstract}
O Brasil é um dos poucos países do mundo a estabelecer a neutralidade da rede como regra. 0 texto proíbe que provedores de internet discriminem certos serviços em detrimento de outros. Isso protege o usuário de ter sua velocidade de conexão diminuída baseada em interesses econômicos. As empresas não poderão, então, diminuir a velocidade da conexão para serviços de voz por IP para dificultar o uso de Skype ou reduzir a banda de um produto de uma empresa concorrente, por exemplo. O Marco Civil da Internet obriga que os registros de conexão dos usuários devem ser guardados pelos provedores de acesso pelo período de um ano, sob total sigilo e em ambiente seguro. Essas informações dizem respeito apenas ao IP, data e horas inicial e final da conexão. 0 texto ainda faculta aos provedores a guarda de registros de Acesso a Aplicações de Internet - que ligam o IP ao uso de aplicações da internet - por seis meses. O Marco Civil estabelece como regra que um conteúdo só pode ser retirado do ar após uma ordem judicial, e que o provedor não pode ser responsabilizado por conteúdo ofensivo postado em seu serviço pelos usuários. Com isso, o projeto pretende evitar a censura na internet: para se provar que um conteúdo é ofensivo, o responsável deve ter o direito ao contraditório na Justiça. ${ }^{11}$
\end{abstract}

A Lei tenta inibir o uso da Internet para fins ilícitos, mesmo tentando "se esconder atrás da tela de um computador" cada vez mais esses criminosos são encontrados e responsabilizados por seus atos, por mais que tentem burlar leis e criar outras redes para tentar se manterem em sigilo, as autoridades estão criando meios eficazes de localizá-los.

Hoje, muitas pessoas estão sendo vitimas de indivíduos que usam a Internet para chantagear, se vingar ou humilhar. Com esta Lei, a vítima pode denunciar o ato às autoridades policiais competentes, bem como judiciais, e ter o conteúdo removido da

10 Disponível em <<http://jus.com.br>>. Acesso em: 29 nov. de 2014.

Conjuntura Global, Vol.3, n. 4, out./dez., 2014, p. 233-243. 
Internet, além de, o praticante do ato ilegal, ser punido pela divulgação do conteúdo.

\section{Considerações Finais}

A internet ainda é um espaço carente de regulamentação legal e, por mais que existam muitas tecnologias e várias especialistas, há pessoas que possuem vasto conhecimento da ferramenta que estão usando e sabem como não serem localizados, não temendo o que pode acontecer, usando uma nova "identidade", em um ambiente virtual que possibilita serem "quem bem entenderem". Assim, mister se faz a criação de leis mais claras e de um sistema mais seguro para localizar essas pessoas para que não continuem impunes. As duas normas apresentadas podem ser consideradas um bom início.

\section{REFERÊNCIAS BIBLIOGRÁFICAS}

1. "Internet: Definição e importância". Disponível em: < http://www.ufpa.br>. Acesso em: 29 nov. de 2014.

2. KLEINA, Nilton. A história da Internet: pré-década de 60 até anos 80. Disponível em: <www.tecmundo.com.br>. Acesso em: 29 nov. de 2014.

3. DUMAS, Véronique. A origem da internet . Disponível em: <www.uol.com.br > Acesso em: 29 nov. de 2014.

4. "Brasil é o terceiro país em número de usuários ativos na internet". Disponível em: <http://www.ibope.com.br/>. Acesso em: 29 nov. de 2014.

5. "Surface Web". Disponível em: <http://pt.wikipedia.org>. Acesso em: 29 nov. 2014

6. KOHN, Stephanie. Twitter, livros e música: o lado 'cult' da deep web. Disponível em: <www.uol.com.br>. Acesso em: 29 nov. de 2014.

7. "Polícia Federal deflagra operação no Amazonas para combater pornografia infantil em Deep Web". Disponível em: <http://uol.com.br/>. Acesso em: 29 nov. de 2014.

8. CABETTE, Eduardo Luiz Santos. "Primeiras impressões sobre a Lei $n^{\circ}$ 12.737/12 e o crime de invasão de dispositivo informático". Disponível em: <http://jus.com.br >. Acesso

\footnotetext{
${ }^{11}$ Disponível em <<http://tecnologia.terra.com.br/>>. Acesso em: 29 nov. de 2014.
}

Conjuntura Global, Vol.3, n. 4, out./dez., 2014, p. 233-243. 
em: 29 nov. de 2014.

9. VARELLA, Guilherme. "Marco Civil da Internet: O que muda na sua vida". Disponível em: <http://tecnologia.terra.com.br/>. Acesso em: 29 nov. de 2014. 